\title{
Effect of Co-Inoculation with Mycorrhiza and Rhizobia on the Nodule Trehalose Content of Different Bean Genotypes
}

\author{
L. Ballesteros-Almanza ${ }^{1}$, J. Altamirano-Hernandez ${ }^{1}$, J.J. Peña-Cabriales ${ }^{3}$, G. Santoyo ${ }^{1}$, \\ J.M. Sanchez-Yañez ${ }^{1}$, E. Valencia-Cantero ${ }^{1}$, L. Macias-Rodriguez ${ }^{1}$, J. Lopez-Bucio ${ }^{1}$, \\ R. Cardenas-Navarro ${ }^{2}$ and R. Farias-Rodriguez ${ }^{1, *}$
}

\author{
${ }^{1}$ Instituto de Investigaciones Quimico-Biologicas. Universidad Michoacana de San Nicolas de Hidalgo, Edificio B1 \\ Ciudad Universitaria. Morelia, Michoacan, Mexico \\ ${ }^{2}$ Instituto de Investigaciones Agropecuarias y Forestales. Universidad Michoacana de San Nicolas de Hidalgo, Km 9.5 \\ Carretera Morelia-Zinapecuaro, Unidad Posta Zootecnica. Tarimbaro, Michoacan, Mexico
}

${ }^{3}$ Departamento de Biotecnologia y Bioquimica, CINVESTAV Campus Guanajuato. Km. 9.6 Carretera Salamanca-Leon. Irapuato, Guanajuato, Mexico

\begin{abstract}
Studies on Rhizobium-legume symbiosis show that trehalose content in nodules under drought stress correlates positively with an increase in plant tolerance to this stress. Fewer reports describe trehalose accumulation in mycorrhiza where, in contrast with rhizobia, there is no flux of carbohydrates from the microsymbiont to the plant. However, the trehalose dynamics in the Mycorrhiza-Rhizobium-Legume tripartite symbiosis is unknown. The present study explores the role of this tripartite symbiosis in the trehalose content of nodules grown under contrasting moisture conditions. Three wild genotypes (P. filiformis, P. acutifolis and P. vulgaris) and two commercial genotypes of Phaseolus vulgaris (Pinto villa and Flor de Mayo) were used. Co-inoculation treatments were conducted with Glomus intraradices and a mixture of seven native rhizobial strains, and trehalose content was determined by GC/MS. The results showed a negative effect of mycorrhizal inoculation on nodule development, as mycorrhized plants showed fewer nodules and lower nodule dry weight compared to plants inoculated only with Rhizobium. Mycorrhizal colonization was also higher in plants inoculated only with Glomus as compared to plants co-inoculated with both microsymbionts. In regard to trehalose, co-inoculation negatively affects its accumulation in the nodules of each genotype tested. However, the correlation analysis showed a significantly positive correlation between mycorrhizal colonization and nodule trehalose content.
\end{abstract}

Keywords: Mycorrhiza-Rhizobium co-inoculation, Trehalose, Drought stress.

\section{INTRODUCTION}

Common beans represent the most important source of dietary protein in developing countries. However, in most of these countries, its cropping has been relegated to marginal production areas, characterized for their poorly developed soils and low nutrient content. Generally speaking, beans are sown under rainfed systems which expose the plant to variable periods of drought. In this regard, an important effort has been made to produce common bean cultivars tolerant to these challenging conditions. An agronomic practice associated with increased yield in these systems is inoculation with Rhizobium. This type of inoculation improves not only the nutritional status of nodulated plants, derived from the biological nitrogen fixation (BNF) process, but recently it has been recognized that this inoculation may also increase drought or osmotic tolerance of nodulated legumes such as acacia, common bean, lotus, and medicago, through the

*Address correspondence to this author at the Instituto de Investigaciones Quimico-Biologicas. Universidad Michoacana de San Nicolas de Hidalgo, Edificio B1 Ciudad Universitaria. Morelia, Michoacan, Mexico; Tel: (+52) 443 3265790; Fax: (+52) 443 3265788;

E-mail: rodolfofarias44@yahoo.com.mx biosynthesis of trehalose ( $\alpha$-D-glucopyranosyl-[1-1]- $\alpha$-Dglucopyranoside) [1-4]. The accumulation of trehalose by different organisms (bacteria, yeast, fungi, nematodes, etc.) has been related to survival under different environmental stresses, like osmotic, low $\mathrm{pH}$, high and low temperatures and dehydration [5-7]. In the nodule, disaccharide is synthesized by the bacteroid, and its accumulation depends on the rhizobial strain, legume genotype and environmental conditions [8]. It was reported that under well-watered conditions, there is a basal amount of trehalose in the nodules, having a negative correlation with the BNF, but under drought conditions, nodule trehalose levels increase significantly and may contribute to maintain BNF under these circumstances [2] and to improve the plant tolerance to drought $[2,8]$. Under field conditions, it was observed that trehalose is detected in seeds from nodulated plants, with a positive correlation with seed longevity [9].

It has been reported that mycorrhizal inoculation increases the plant's tolerance to drought. The most accepted mechanism for this effect is the improvement of water-use efficiency of the mycorrhized plant [10-13]. Interestingly, it is also known that ecto and endo mycorrhizae synthesize trehalose $[14,15]$. Nevertheless, in this case, it was demon- 
strated trough the use of ${ }^{14} \mathrm{C}$ that there is no carbohydrate flux from the fungi to the plant [16], and fungi trehalose is mostly localized at the spores where it may serve, as in Trichoderma and Aspergillus, to increase the survival of the spores 17-18]. In a recent in vitro study, it was observed that mycorrhizal roots under osmotic stress mobilized trehalose from the mycorrhizal root to the external mycelia (FariasRodriguez, unpublished data), supporting the idea that trehalose biosynthesis in mycorrhizal symbiosis is only localized in fungal tissues and does not contribute to plant stress tolerance as in Rhizobium.

In the case of co-inoculation (rhizobia and mycorrhiza) experiments on legumes, most of the reports argue for a synergistic effect of both microsymbionts on plant development [19]. However, in common bean, examples in the literature show a negative effect of mycorrhiza on nodule development [20]. The objective of this work was to study the effect of mycorrhiza inoculation on trehalose accumulation in the nodule.

\section{MATERIALS AND METHODS}

\section{Biological Material}

The common bean genotypes used here were the wild accessions Phaseolus filiformis P1535309, P. acutifolius G40142 and $P$. vulgaris P1325687, and the commercial cultivars $P$ vulgaris $\mathrm{cv}$. Pinto Villa and $P$. vulgaris cv. Flor de Mayo. The seeds were donated by Jorge Acosta Gallegos from INIFAP-Celaya.

Glomus intraradices spores were donated by Javier Villegas from IIQB-UMSNH and maintained at $-70^{\circ} \mathrm{C}$ in a $50 \%$ glycerol solution. The Rhizobium strains used (Fcin1, Fcin2, Fcin3, Fcin4, Fcin5, Fcin6, and Fcin7) were isolated in a previous experiment [9]. Stock cultures were maintained at $-70^{\circ} \mathrm{C}$ in PY medium (in $\mathrm{g} \mathrm{L}^{-1}$ : yeast extract $3, \mathrm{CaCl}_{2} \cdot 2 \mathrm{H}_{2} \mathrm{O} 1$, casein peptone 5), containing 50\% (v/v) glycerol.

\section{Inoculation Treatment}

Seeds were surface disinfected with $2.5 \mathrm{M} \mathrm{NaOCl}$ for 5 min and rinsed with sterile distilled water before use. Three inoculation treatments were imposed as follows: a) Rhizobium inoculation was performed by soaking the seeds for $1 \mathrm{~h}$ in a mixture of native rhizobial strains prepared as described by Altamirano-Hernandez et al. [9]; b) Glomus inoculation was performed during sowing by adding to each seed $1 \mathrm{~mL}$ of a Glomus spore suspension (30 spores $\left.\mathrm{mL}^{-1}\right)$; c) coinoculation was performed by first inoculating Rhizobium as described previously, then $1 \mathrm{~mL}$ of a Glomus spore suspension was added to each seed during sowing. Control plants were not inoculated, instead they were watered with a Jensen solution (in $\mathrm{g} \mathrm{L}^{-1}: 1 \mathrm{Ca}\left(\mathrm{H}_{2} \mathrm{PO}_{4}\right)_{2} \cdot \mathrm{H}_{2} \mathrm{O}, 0.2 \mathrm{~K}_{2} \mathrm{HPO}_{4}, 0.2$ $\mathrm{MgSO}_{4} .7 \mathrm{H}_{2} \mathrm{O}, 0.2 \mathrm{NaCl}, 0.1 \mathrm{FeCl}_{2} .4 \mathrm{H}_{2} \mathrm{O}$, and $1 \mathrm{~mL}$ of mineral solution $\left[2.86\right.$ boric acid, $0.22 \mathrm{ZnSO}_{4} .7 \mathrm{H}_{2} \mathrm{O}, 1,81$ $\left.\mathrm{MnCl}_{2} .7 \mathrm{H}_{2} \mathrm{O}, 0.09 \mathrm{~K}_{2} \mathrm{MoO}_{4}\right]$ ) containing $0.05 \% \mathrm{KNO}_{3}$.

\section{Drought Stress}

Plants from different inoculation treatments (previously described) were watered every three days, and once a week a Jensen solution was used. Drought stress was imposed on plants at the flowering stage (R7) by suspending watering for
16 days. At the end of this period, plant total biomass and leaf area were recorded. From the Rhizobium and coinoculation treatments, nodules were harvested by hand and nodule number and dry weight were measured.

Root samples were collected from co-inoculated and Glomus-inoculated plants to measure mycorrhizal colonization.

\section{Trehalose Analysis}

Nodule trehalose was extracted by grinding the nodules in boiling $80 \%(\mathrm{v} / \mathrm{v})$ ethanol and evaporated to dryness before resuspension in $1 \mathrm{~mL}$ of $80 \%(\mathrm{v} / \mathrm{v})$ ethanol. Aliquots of $100 \mu \mathrm{L}$ from each sample were derivatized to obtain the aldonitrile peracetylated forms of the sugars, $25 \mu \mathrm{g}$ of perseitol were added as internal standard, and then analyzed by gas chromatography-mass spectrometry (HP6850-HP5973) on an HP-5 MS column (Agilent Technologies, Palo Alto, CA) as described by Macias-Rodriguez et al. [21].

\section{RESULTS}

\section{Nodulation Parameters}

In general terms, it was observed that co-inoculation of Glomus and Rhizobium in bean plants had a negative effect on nodulation parameters (Figs. 1 and 2). In this sense, the wild accession of $P$. vulgaris $\mathrm{P} 1325687$ showed the highest number of nodules under both watering regimes and inoculation treatments. In the well-watered treatment (Fig. 1a), $P$. vulgaris P1325687 presented on average 500 nodules per plant when inoculated only with the rhizobial mixture, but when co-inoculated with Glomus, the number of nodules in this bean genotype significantly decreased $(p<0.05)$ to an average of 300 per plant. The commercial $P$. vulgaris genotypes (Flor de Mayo and Pinto Saltillo) inoculated only with Rhizobium presented 65 nodules per plant on average, but when co-inoculated with Glomus, the number of nodules decreased to 45. P. filiformis and P. acutifolius showed a low number of nodules, with an average of 12 nodules per plant; under co-inoculation they showed an average of 7 nodules per plant.

When drought was imposed on these bean plants, the number of nodules decreased in the two inoculation treatments when compared with their well-watered counterparts (Fig. 1b). P. vulgaris $\mathrm{P} 1325687$ had 350 nodules per plant when inoculated with Rhizobium, and only 100 when coinoculated with Glomus. Under watering conditions, there was a significant difference among the two commercial bean cultivars. P. vulgaris $\mathrm{cv}$. Flor the Mayo presented 45 nodules when inoculated with Rhizobium and 35 when the mycorrhiza was co-inoculated. Interestingly, $P$. vulgaris $\mathrm{cv}$. Pinto Saltillo had 10 nodules when inoculated only with Rhizobium and 40 when the mycorrhiza was co-inoculated. This was the only case recorded in this work in which the number of nodules increased with Glomus inoculation. In contrast, $P$. filiformis and $P$. acutifolius had 10 nodules with rhizobial inoculation and 4 with co-inoculation under this drought treatment.

Variability in the dry weight of nodules among the different bean genotypes was lower as compared to that recorded for the total number of nodules (Figs. 1 and 2). Under 
A)

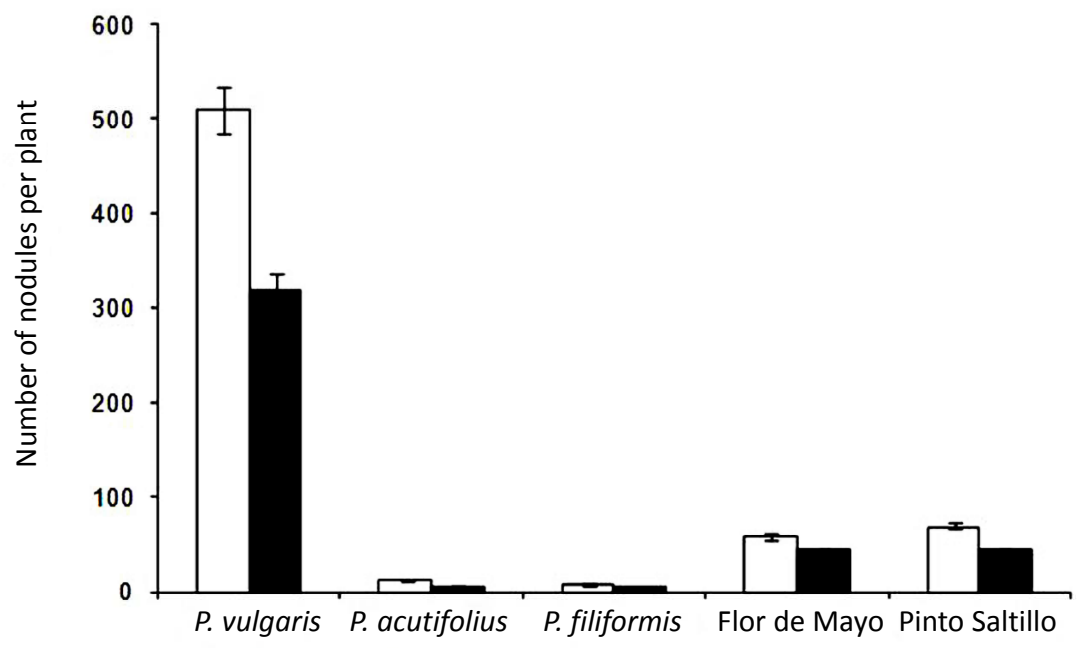

B)

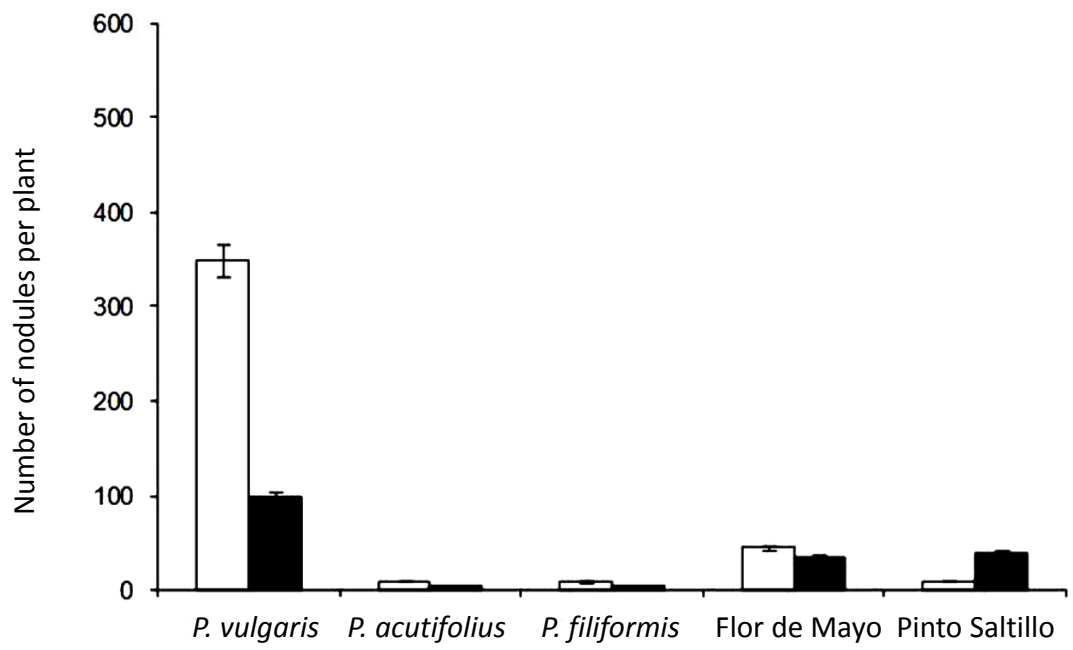

Fig. (1). Number of nodules per plant under A) well-watered treatment and B) drought stress treatment. White bars represent nodules from plants inoculated only with Rhizobium; black bars represent nodules from plants co-inoculated with Rhizobium and Glomus.

well-watered conditions (Fig. 2a), when plants were inoculated with the rhizobial mixture, $P$. acutifolius showed the largest nodules, with an average dry weight of $0.55 \mathrm{mg}$ nodule $^{-1}$. P. vulgaris P1325687 nodules weighed $0.43 \mathrm{mg}$ on average. The last three genotypes had on average nodules of $0.21 \mathrm{mg}$. Under the co-inoculation treatment, the weight of nodules significantly $(p<0.05)$ decreased in $P$. vulgaris P1325687 (0.35 mg nodule $\left.\mathrm{e}^{-1}\right), P$. acutifolius $(0.23 \mathrm{mg}$ nodule $^{-1}$ ) and $P$. vulgaris cv. Pinto Saltillo ( $\left.0.15 \mathrm{mg}_{\text {nodule }}{ }^{-1}\right)$.

Nodule weight decreased under drought condition (Fig. 2b). As in well-watered plants, $P$. acutifolius had the largest nodules when inoculated only with Rhizobium, with an average dry weight of $0.38 \mathrm{mg}$ nodule $\mathrm{e}^{-1}$, followed by $P$. vulgaris P1325687 with $0.30 \mathrm{mg}$ nodule ${ }^{-1}$. The smallest nodules were reordered in $P$. vulgaris cv. Pinto Saltillo with an average of $0.10 \mathrm{mg}$ nodule ${ }^{-1}$. When these bean genotypes were coinoculated with Glomus, nodule weight decreased significantly $(p<0.05)$ in all genotypes, with a maximum value of
$0.19 \mathrm{mg}$ nodule $\mathrm{e}^{-1}$ in $P$. vulgaris $\mathrm{P} 1325687$, and a minimum of $0.1 \mathrm{mg}$ nodule $\mathrm{e}^{-1}$ in $P$. acutifolius. In contrast, $P$. vulgaris $\mathrm{cv}$. Pinto Saltillo nodules showed significant $(p<0.05)$ increases, with $0.16 \mathrm{mg}$ nodule ${ }^{-1}$.

\section{Nodule Trehalose Content}

The effect of mycorrhizal co-inoculation on nodule trehalose content is shown in Table 1. Mycorrhizal co-inoculation caused a decrease in trehalose content of nodules. Under well-watered condition, in plants inoculated only with Rhizobium, the average trehalose content in the nodules was $36 \mathrm{mg} \mathrm{g}^{-1}$, the highest value corresponded to $P$. filiformis $(50$ $\left.\mathrm{mg} \mathrm{g}^{-1}\right)$, and the lowest to P. vulgaris cv Flor de Mayo (20 $\mathrm{mg} \mathrm{g}^{-1}$ ). In the co-inoculation treatment, the average nodule trehalose content of these five genotypes significantly $(p<0.05)$ decreased to $16 \mathrm{mg} \mathrm{g}^{-1}$, the maximum value of 25 $\mathrm{mg} \mathrm{g}^{-1}$ corresponding to $P$. filiformis and the minimum of 10 $\mathrm{mg} \mathrm{g}^{-1}$ to $P$. acutifolius and $P$. vulgaris cv. Flor de Mayo. 
A)

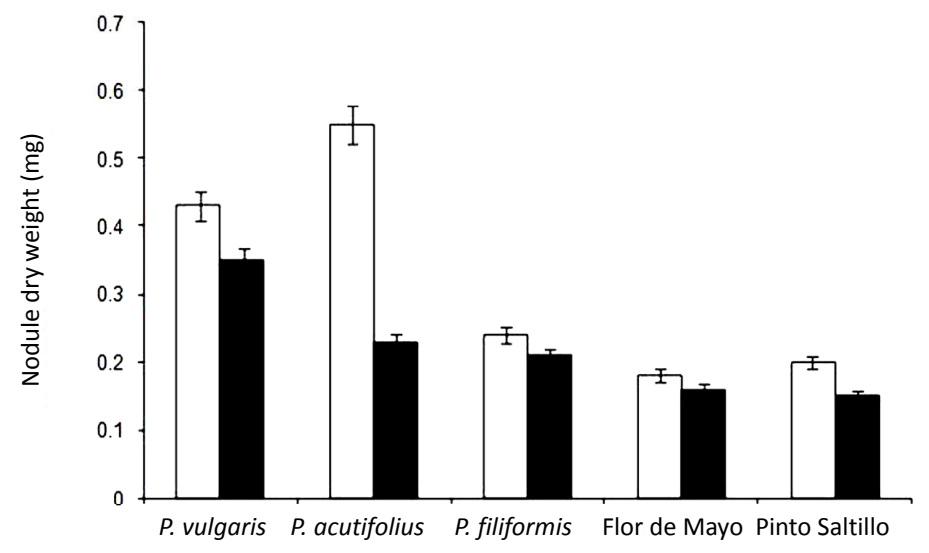

B)

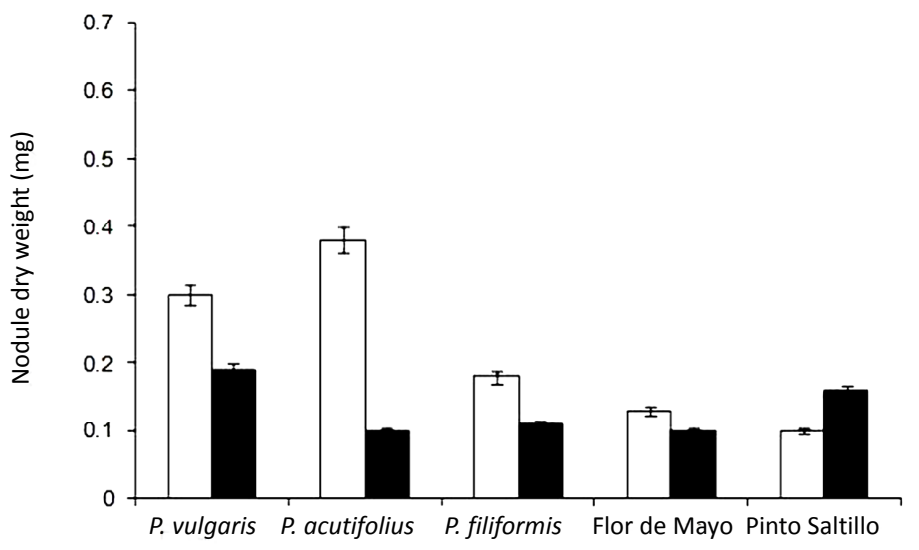

Fig. (2). Nodule dry weight under A) well-watered treatment and B) drought stress treatment. White bars represent nodules from plants inoculated only with Rhizobium; black bars represent nodules from plants co-inoculated with Rhizobium and Glomus.

Table 1. Effect of Mycorrhizal Inoculation and Drought Stress on Nodule Trehalose Content

\begin{tabular}{|l|c|c|c|c|}
\hline \multirow{2}{*}{} & \multicolumn{3}{|c|}{ Nodule Trehalose Content $\left(\mathbf{m g ~ g}^{-1}\right)$} \\
\cline { 2 - 5 } & $\mathbf{N}$ & Well-Watered & \multicolumn{2}{|c|}{ Drought Stressed } \\
\hline \hline P. filiformis & 50 & 12 & 90 & N+M \\
\hline P. acutifolius & 30 & 10 & 70 & 72 \\
\hline P. vulgaris & 40 & 25 & 40 & 40 \\
\hline P. vulgaris cv. Flor de Mayo & 20 & 10 & 60 & 30 \\
\hline P. vulgaris cv. Pinto Saltillo & 40 & 22 & 35 \\
\hline
\end{tabular}

N: inoculated with Rhizobium

N+M: inoculated with Rhizobium and Glomus.

Under drought stress, trehalose content of nodules significantly $(p<0.05)$ increased in both inoculation treatments in comparison to their well-watered counterparts. The average nodule trehalose content for the five genotypes with Rhizobium inoculation in this water regime was of $67 \mathrm{mg} \mathrm{g}^{-1}$. The highest trehalose content was recorded in nodules of $P$. vulgaris P1325687 (90 $\mathrm{mg} \mathrm{g}^{-1}$ ), and the lowest in $P$. vulgaris cv. Flor de Mayo $\left(45 \mathrm{mg} \mathrm{g}^{-1}\right)$. In the co-inoculation treatment, the trehalose content of nodules significantly $(p<0.05)$ decreases in all genotypes, with an average value of $31 \mathrm{mg} \mathrm{g}^{-1}$. The maximum trehalose value corresponded to $P$. filiformis $\left(40 \mathrm{mg} \mathrm{g}^{-1}\right)$ and the minimum to P. vulgaris cv. Flor de Mayo $\left(18 \mathrm{mg} \mathrm{g}^{-1}\right)$. 


\section{Mycorrhizal Colonization}

To better understand the negative effect of Glomus inoculation on the nodule parameters described previously, mycorrhizal colonization was recorded and the results are shown in Fig. (3). Interestingly, mycorrhizal colonization was higher when the plants were only inoculated with Glomus in all genotypes evaluated, and decreased when the co-inoculation Glomus-Rhizobium was performed. Under well-watered conditions, mycorrhizal colonization among the five evaluated bean genotypes was quite uniform, with an average colonization of $22 \%$. The maximum value was recorded for P. vulgaris cv. Pinto Saltillo $(27 \%)$ and the minimum for $P$. vulgaris cv. Flor de Mayo (15\%). When co-inoculated with Rhizobium, mycorrhizal colonization decreased to an average of $15 \%$. The highest value was $18 \%$ for P. filiformis and P. vulgaris P1325687, and the lowest value was $10 \%$ for $P$. vulgaris $\mathrm{cv}$. Flor de Mayo.
Under drought stress it was observed that, as opposed to nodulation, mycorrhizal colonization increased, with an average value of $37 \%$. P . filiformis showed the highest colonization with 50\%, while $P$. vulgaris $\mathrm{cv}$. Flor de Mayo showed the lowest with $10 \%$. In the co-inoculation treatment, Glomus colonization significantly $(p<0.05)$ decreased, as occurred under well-watered conditions, with an average of $21 \%$, the maximum value being for $P$. filiformis (35\%) and the minimum for P. vulgaris $\mathrm{cv}$. Flor de Mayo (5\%).

\section{Correlation Between Nodulation and Mycorrhization}

When a correlation analysis was performed to evaluate the effect of mycorrhiza on nodule parameters, it was interesting to observe that under well watered conditions, comparing data from the five bean genotypes, the correlation indices showed a positive relationship between Glomus colonization and nodulation (although it wasn't statistically

A)

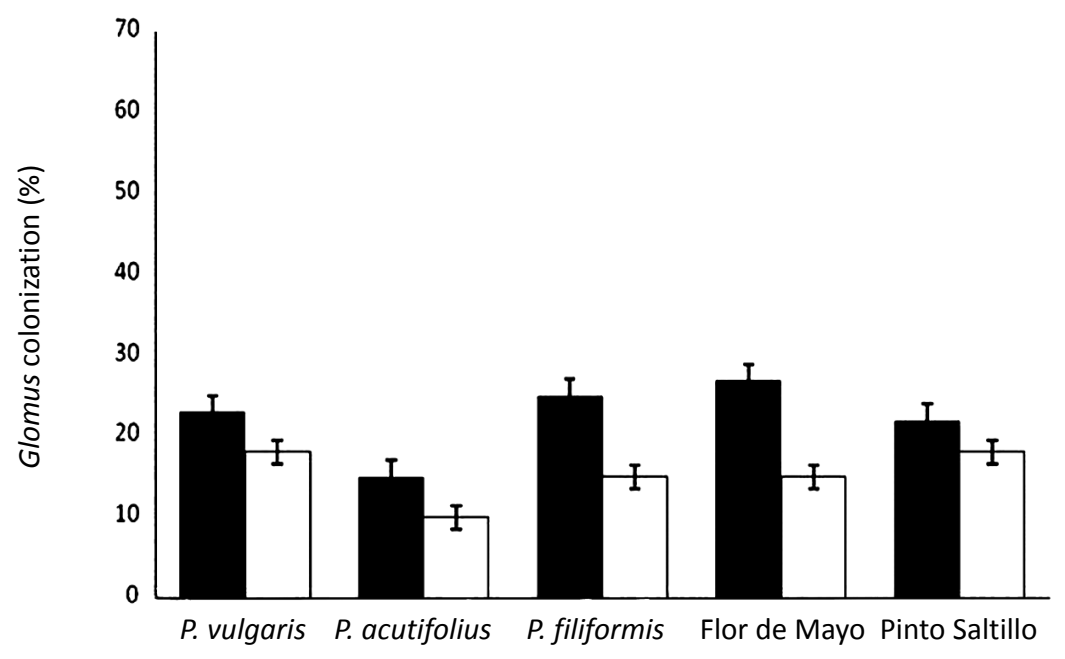

B)

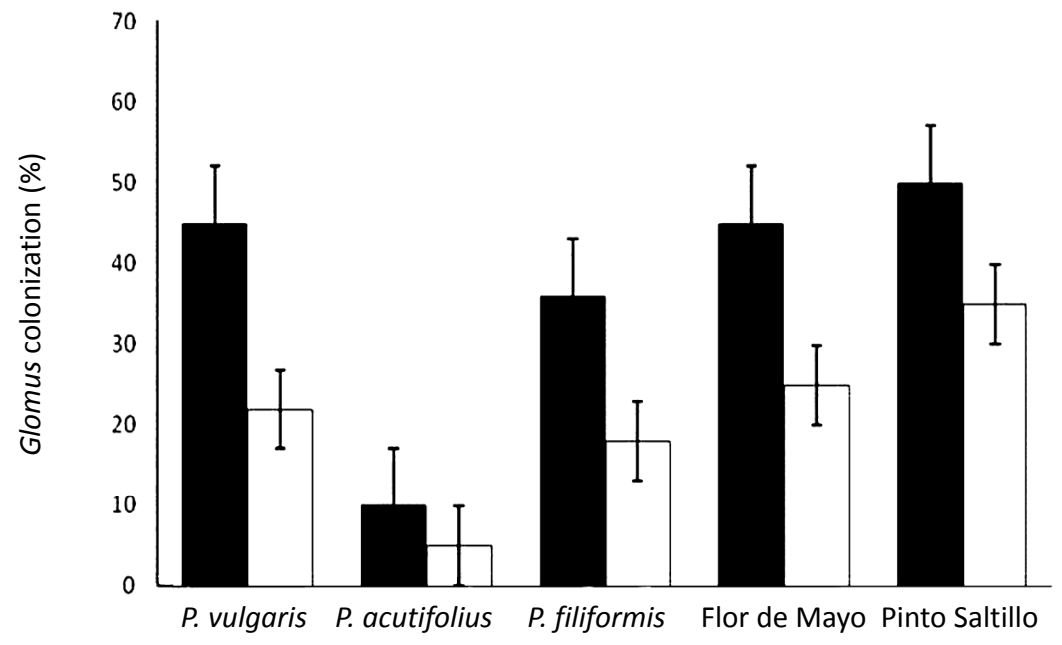

Fig. (3). Percentage of Glomus colonization under: A) well-watered treatment and B) drought stress treatment. White bars represent nodules from plants inoculated only with Glomus; black bars represent nodules from plants co-inoculated with Rhizobium and Glomus. 
significant). This would indicate that bean genotypes that have the highest mycorrhizal colonization showed the highest number of nodules, nodule dry weight and nodule trehalose content (Fig. 4a), regardless of the fact that individually, in each genotype mycorrhizae decreased the values of these parameters. The correlation index values for Glomus colonization were $\mathrm{r}=0.38$ for nodule number, $\mathrm{r}=0.63$ for nodule dry weight, and $r=0.48$ for trehalose content. However, under drought conditions, some changes were observed in these correlations indices (Fig. 4b). The number of nodules had a negative correlation with mycorrhization $(r=0.15)$. Even though the correlation index observed with nodule dry weight decreased, a positive correlation was still observed $(\mathrm{r}=0.26)$. Interestingly, trehalose correlation index increased to a significant value of 0.98 .

\section{Effect of Co-Inoculation on Bean Biomass and Leaf Area}

Plant leaf area with the different inoculation treatments under both water regimes is shown in Table $\mathbf{2}$. Under wellwatered conditions, the response of the five bean genotypes to the different inoculation treatments was very heterogeneous. Nevertheless, control plants that where chemically fertilized showed the greatest leaf area $\left(149 \mathrm{~cm}^{2}\right)$, followed by the plants co-inoculated with Rhizobium and Glomus (138 $\mathrm{cm}^{2}$ ). Plants inoculated with Rhizobium had an average leaf area of $118 \mathrm{~cm}^{2}$, and the minimum recorded value corresponded to plants inoculated with Glomus $\left(103 \mathrm{~cm}^{2}\right)$. Also, considering only the inoculated treatments, it was observed that in $P$. filiformis and $P$. acutifolius plants, co-inoculation resulted in a negative effect by reducing the leaf area when compared to the maximum area obtained under inoculation, which corresponded to Rhizobium inoculation. On the other hand, co-inoculation had a positive effect on $P$. vulgaris P1325687 and $P$. vulgaris cv. Flor de Mayo genotypes, which showed the greatest leaf area under this treatment in comparison to single inoculations.

Under drought stress, bean plants inoculated with Glomus presented the greatest leaf area $\left(96 \mathrm{~cm}^{2}\right)$, followed by plants inoculated with Rhizobium $\left(90 \mathrm{~cm}^{2}\right)$. Leaf area in fertilized control plants decreased to $85 \mathrm{~cm}^{2}$, and the smallest leaf area was recorded in co-inoculated plants $\left(84 \mathrm{~cm}^{2}\right)$. Again, considering only inoculation treatments, it was observed that in $P$. acutifolius and $P$. vulgaris $\mathrm{P} 1325687$, the maximum leaf area was obtained under Glomus inoculation, and co-inoculation negatively affected this parameter. On the other hand, $P$. acutifolius and P. vulgaris cv. Flor de Mayo showed greater leaf area with Rhizobium inoculation, being negatively affected by co-inoculation. P. vulgaris $\mathrm{cv}$. Pinto
A)

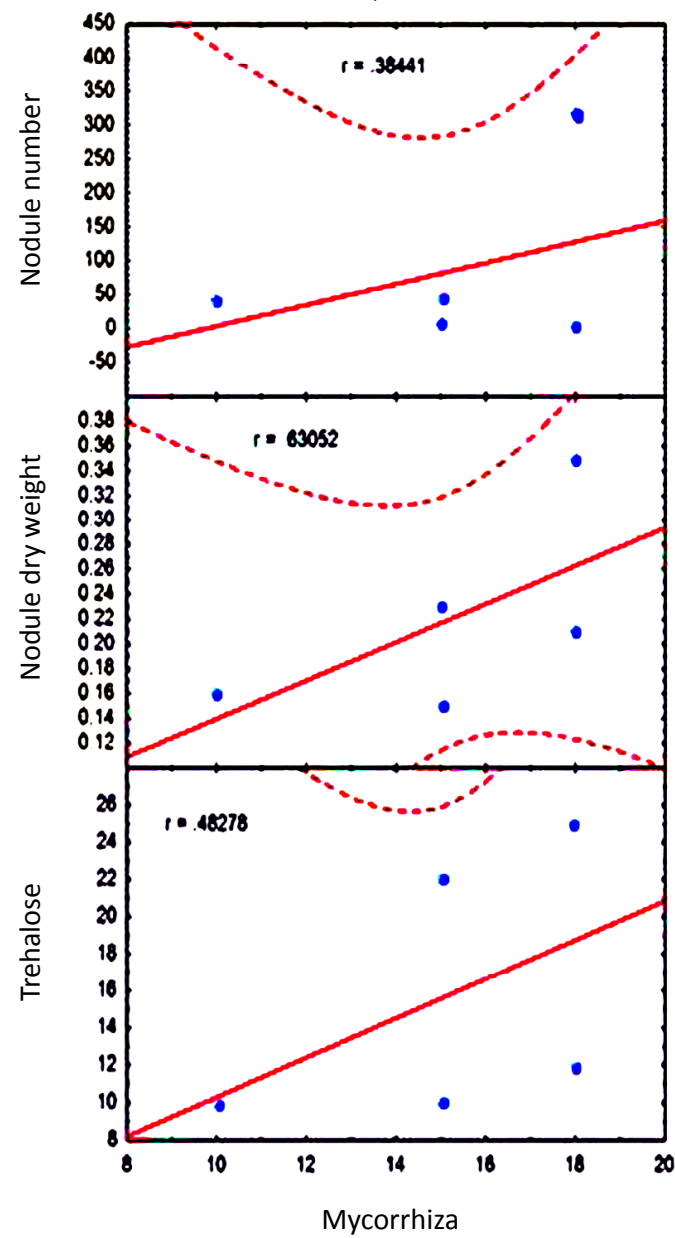

B)

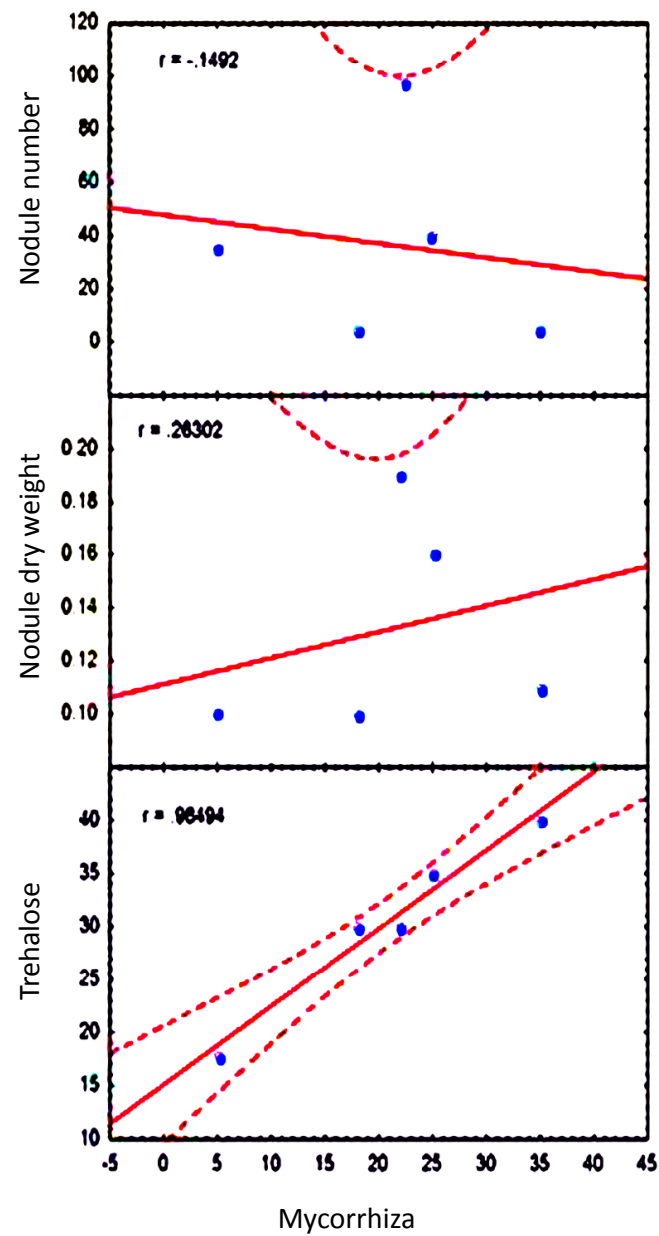

Fig. (4). Correlation indexes between mycorrhiza colonization and nodule parameters; A) well-watered treatment and B) drought stress treatment. Dashed lines represent confidence interval at $\mathrm{p}<0.05$. 
Table 2. Effect of Rhizobial and Mycorrhizal Inoculation on Leaf Area of Phaseolus Under two Watering Regimes

\begin{tabular}{|c|c|c|c|c|c|c|c|c|}
\hline & \multicolumn{8}{|c|}{ Leaf Area $\left(\mathrm{cm}^{2}\right)$} \\
\hline & \multicolumn{4}{|c|}{ Well-Watered } & \multicolumn{4}{|c|}{ Drought Stressed } \\
\hline P. filiformis & $34 \mathrm{a}$ & $32 \mathrm{a}$ & $24 \mathrm{a}$ & $28 \mathrm{a}$ & $38 \mathrm{a}$ & $18 \mathrm{~b}$ & $15 b$ & $20 \mathrm{~b}$ \\
\hline P. vulgaris & $65 \mathrm{a}$ & $110 \mathrm{bc}$ & $91 b$ & $81 \mathrm{~b}$ & $40 \mathrm{a}$ & $53 \mathrm{ab}$ & $66 \mathrm{~b}$ & $66 \mathrm{~b}$ \\
\hline P. vulgaris cv. Flor de Mayo & $160 \mathrm{a}$ & $210 \mathrm{~b}$ & $162 \mathrm{a}$ & $210 \mathrm{~b}$ & $155 b$ & $106 \mathrm{a}$ & $90 \mathrm{a}$ & $152 b$ \\
\hline P. vulgaris cv. Pinto Saltillo & $152 \mathrm{a}$ & $180 \mathrm{a}$ & $185 \mathrm{a}$ & $120 \mathrm{a}$ & $115 \mathrm{a}$ & $149 b$ & $100 \mathrm{a}$ & $86 a$ \\
\hline
\end{tabular}

$\mathrm{N}$ : inoculated with Rhizobium.

N+M: inoculated with Rhizobium and Glomus.

M: inoculated with Glomus.

C: chemically fertilized control plants.

Different letters in the same line represent significant differences at $\mathrm{p}<0.05$, under the same irrigation treatment.

Table 3. Effect of Rhizobial and Mycorrhizal Inoculation on Total Biomass of Phaseolus Under two Watering Regimes

\begin{tabular}{|c|c|c|c|c|c|c|c|c|}
\hline & \multicolumn{8}{|c|}{ Total Biomass (mg plant ${ }^{1}$ ) } \\
\hline & \multicolumn{4}{|c|}{ Well-Watered } & \multicolumn{4}{|c|}{ Drought Stressed } \\
\hline P. filiformis & $1.38 \mathrm{a}$ & $.72 b$ & $0.72 b$ & $0.6 \mathrm{a}$ & $.52 \mathrm{a}$ & $.31 b$ & $.37 b$ & $.28 b$ \\
\hline P. vulgaris & $1.6 \mathrm{a}$ & $1.6 \mathrm{a}$ & $.96 \mathrm{a}$ & $1.2 \mathrm{a}$ & $1.2 \mathrm{a}$ & $.45 \mathrm{~b}$ & $.65 \mathrm{~b}$ & $.35 b$ \\
\hline P. vulgaris cv Flor de Mayo & $2.4 \mathrm{a}$ & $1.5 \mathrm{~b}$ & $2.0 \mathrm{a}$ & $1.4 \mathrm{~b}$ & $1.85 \mathrm{a}$ & $1.15 \mathrm{~b}$ & $1.31 \mathrm{~b}$ & $0.9 \mathrm{~b}$ \\
\hline P. vulgaris cv Pinto Saltillo & $2.7 \mathrm{a}$ & $1.45 \mathrm{~b}$ & $2.1 \mathrm{a}$ & $0.5 \mathrm{a}$ & $2.0 \mathrm{a}$ & $1.0 \mathrm{~b}$ & $1.8 \mathrm{a}$ & $0.9 \mathrm{a}$ \\
\hline
\end{tabular}

$\mathrm{N}$ : inoculated with Rhizobium.

N+M: inoculated with Rhizobium and Glomus.

M: inoculated with Glomus.

C: chemically fertilized control plants.

Different letters in the same line represent significant differences at $\mathrm{p}<0.05$, under the same irrigation treatment.

Saltillo represented the only case in which a positive effect of co-inoculation was observed, with maximum leaf area.

The effect of inoculation on total biomass is shown in Table 3. In this case, the Rhizobium inoculation produced the highest biomass of all five genotypes tested, both under wellwatered and drought stressed plants. The total biomass for Rhizobium inoculated plants under well-watered conditions was $2 \mathrm{mg}$ plant $^{-1}$, followed by plants inoculated with Glomus, with a biomass of $1.5 \mathrm{mg}^{\text {plant }}{ }^{-1}$, and of the inoculated plants, those that were co-inoculated showed the lower biomass (1.4 mg plant ${ }^{-1}$ ). Plants under drought stress inoculated with Rhizobium showed a biomass of $1.4 \mathrm{mg} \mathrm{plant}^{-1}$; plants inoculated with Glomus showed a biomass of $1 \mathrm{mg}$ plant $^{-1}$, and those co-inoculated showed $0.7 \mathrm{mg} \mathrm{plant}^{-1}$.

Considering the plant biomass obtained under wellwatered conditions as $100 \%$ of growth for the different inoculation treatments, inhibition caused by drought was re- corded and the results are shown in Fig. (5). Although there was no statistical significance $(p<0.05)$ among inoculation treatments, the bean plants less affected by drought were the chemically fertilized ones with an average of $30 \%$ biomass reduction when compared to their well-water counterpart.

Among the inoculated treatments, plants inoculated with Rhizobium were the least affected by drought (33\% biomass reduction), followed by plants inoculated with Glomus (37\% biomass reduction), and the plants most sensitive to drought were the ones co-inoculated, with an average biomass reduction of $44 \%$.

\section{DISCUSSION}

The biosynthesis of trehalose has been correlated with tolerance to different types of stress. Although this carbohydrate is widespread in nature, it is considered to be absent in superior vascular plants in the past decade. Several efforts 


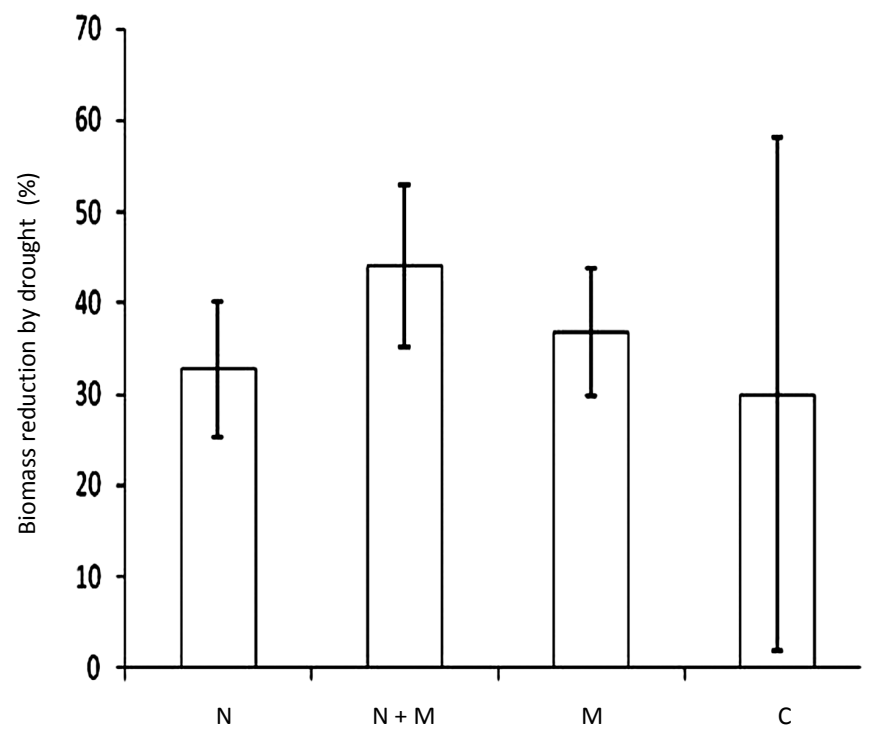

Fig. (5). Percentage of biomass reduction caused by drought in comparison to well-watered plants among the different inoculation treatments. N: Plants inoculated with rhizobia. N+M: Plants co-inoculated with Glomus and rhizobia. M: Plants inoculated with Glomus. C: Non-inoculated control plants.

have been made to obtain transgenic plants that express the microbial genes for the synthesis of trehalose, with the aim of increasing plants' tolerance to dehydration [22, 23]. Up until today, the presence of trehalose genes in several plants has been reported [24-26], but the carbohydrate has been rarely detected [27], and assays on transgenic plants continue [28-31]. On the other hand, when plants are in symbiosis with different microorganisms, trehalose is commonly detected. The role of trehalose in these interactions has been mostly studied in the Rhizobium-legume symbiosis and less work has been conducted in regard to fungi-plant interaction.

Today, there are no reports in the literature that have considered the effect of co-inoculation with bacteria and fungi on plant trehalose accumulation. In this sense, studies on coinoculation of Rhizobium and mycorrhiza on legumes have focused on mycorrhiza performance and its effect on plant nutrient uptake and, only in a few cases, on plant drought tolerance. For example, in faba bean (Vicia faba) it has been reported that mycorrhizal inoculation increased nodule number when compared to non-mycorrhized plants, and this positive effect on nodulation was also observed under drought conditions, but when plant drought tolerance was discussed, only the mycorrhizal parameters were considered [32].

There are scarce reports on common bean, and these reports point to a negative effect of mycorrhiza on nodule development and nitrogen fixation [20,33]. Therefore, considering all the reports that establish that trehalose accumulation in legume nodules is related to increased plant drought stress, the aim of the present work was to analyze the effect of mycorrhizal colonization on nodulated common bean based on parameters related to drought tolerance.

This work is in agreement with previous reports on common bean, which support the idea that co-inoculation has a negative effect on the microsymbionts that are involved in this process [33], since nodulation and mycorrhizal colonization were higher when inoculated independently, and both parameters decreased with co-inoculation. Of the three wild beans used in this work, $P$. filiformis and $P$. acutifolius showed the lowest number of nodules in all treatments. This could be attributed to the origin of the rhizobial strains, which were isolated from a field devoted to common bean production and may not be the most adequate strains for these two genotypes. On the contrary, there was no difference in mycorrhizal colonization between these three genotypes under well-watered conditions. P. filiformis showed high mycorrhizal colonization under drought conditions. When co-inoculation was assayed, both mycorrhizal colonization and nodulation decreased in all bean genotypes tested. This behavior was probably due to a competition for plant photosynthates between both microorganisms, imposed by the experimental conditions used at this work. Interestingly, when the data from the five bean genotypes were combined to compute the correlation indexes, the opposite correlations were observed

Under well-watered conditions, nodule number and dry weight correlate positively with mycorrhizal colonization. In other words, among the different bean genotypes, the higher the mycorrhization the higher the nodulation; however, as mentioned earlier, this type of co-inoculation reduced the value of these two parameters when compared to plants inoculated only with Rhizobium. In drought stressed plants, correlation indexes between nodulation and mycorrhizal colonization parameters were negative, indicating that nodulation is more sensitive to dehydration than the mycorrhiza. Also, as mycorrhiza is more widely distributed in the root, there is the possibility that this fungus could better exploit the limited photosynthates available in this condition.

In regard to trehalose accumulation, in co-inoculation treatments there was a decrease in its nodule content when compared with plants inoculated only with rhizobia. It was observed that under both watering regimes, the correlation index was positive, and under drought it became highly significant ( $\mathrm{r}=0.98)$. Up until today, the precise biochemical and 
molecular control of trehalose biosynthesis in the nodule is not understood. Although some data suggest that nodule trehalose could be mobilized to the plant, there is no conclusive evidence. Therefore, if there is a trehalose release from the nodule under drought to the plant tissue, it would be possible, under this circumstance, for the mycorrhiza to utilize it and export the trehalose to the external mycelia and spores, and this fungal dependency on nodule trehalose may provoke this high correlation index. The mobilization of trehalose from the mycorrhizal roots to the external mycelia has been previously observed in an experiment using as a study model transformed carrot roots, which once mycorrhized, were submitted to osmotic stress; it was observed that under these conditions, there was a higher trehalose content in the external mycelia as compared to the non-stressed controls (FariasRodriguez, unpublished data). As this work focused on reproducing the soil environment under field conditions, it's very difficult to understand the basic mechanisms underlying this observation; in order to elucidate this relationship, future work should be conducted with the use of in vitro systems, that will allow a better understanding of the phenomena reported here.

When considering biomass production as an estimate of drought tolerance, it was observed once again that plants inoculated only with rhizobia or mycorrhiza were less affected by drought, whereas when co-inoculated, a higher decrease in biomass production was observed as compared to the plants' well-watered counterparts. In conclusion, the results presented in this work support the idea that the use of rhizobial or mycorrhizal inoculation separately would result in better bean drought tolerance than the co-inoculation treatment.

\section{REFERENCES}

[1] Räsänen LA, Saijets S, Jokinen K, Lindström K. Evaluation of the roles of two compatible solutes, glycine betaine and trehalose, for the Acacia senegal-Sinorhizobium symbiosis exposed to drought stress. Plant Soil 2004; 260: 237-51.

[2] Jimenez-Zacarias JJ, Altamirano-Hernandez J, Peña-Cabriales JJ. Nitrogenase activity and trehalose content of nodules of droughtstressed common beans infected with effective (Fix+) and ineffective (Fix-) rhizobia. Soil Biol Biochem 2004; 36: 1975-81.

[3] Lopez M, Herrera-Cervera JA, Lluch C, Tejera NA. Trehalose metabolism in root nodules of the model legume Lotus japonicus in response to salt stress. Physiol Plant 2006; 128: 701-9.

[4] Lopez M, Tejera NA, Iribarne C, Lluch C, Herrera-Cervera JA. Trehalose and trehalase in root nodules of Medicago truncatula and Phaseolus vulgaris in response to salt stress. Physiol Plant 2008; 134: 575-82.

[5] Doehlemann G, Berndt P, Hahn M. Trehalose metabolism is important for heat stress tolerance and spore germination of Botrytis cinerea. Microbiology 2006; 152: 2625-34.

[6] McIntyre HJ, Davies H, Hore TA, Miller SH, Dufour JP, Ronson CW. Trehalose biosynthesis in Rhizobium leguminosarum bv. trifolii and its role in desiccation tolerance. Appl Environ Microbiol 2007; 73: 3984-92.

[7] Mahmud SA, Nagahisa K, Hirasawa T, Yoshikawa K, Ashitani K, Shimizu $\mathrm{H}$. Effect of trehalose accumulation on response to saline stress in Saccharomyces cerevisiae. Yeast 2009; 26: 17-30.

[8] Farias-Rodriguez R, Mellor RB, Arias C, Peña-Cabriales JJ. The accumulation of trehalose in nodules of several cultivars of common bean (Phaseolus vulgaris) and its correlation with resistance to drought stress. Physiol Plant 1998; 102: 352-9.

[9] Altamirano-Hernandez J, Lopez MG, Acosta-Gallegos JA, FariasRodriguez R, Peña-Cabriales JJ. Influence of soluble sugars on seed quality in nodulated common bean (Phaseolus vulgaris L.): The case of trehalose. Crop Sci 2007; 47: 1193-205.

[10] Ahmad Khan I, Ahmad S, Mirza S. Yield and water use efficiency (WUE) of Avena sativa as influenced by vesicular arbuscular mycorrhizae (VAM). Asian J Plant Sci 2003; 2: 371-3.

[11] Bolandnazar S, Aliasgarzad N, Neishabury MR, Chaparzadeh N. Mycorrhizal colonization improves onion (Allium cepa $\mathrm{L}$.) yield and water use efficiency under water deficit condition. Scientia Hort 2007; 114: 11-15.

[12] Farahani A, Lebaschi H, Hussein M, Hussein SA, Reza VA, Jahanfar D. Effects of arbuscular mycorrhizal fungi, different levels of phosphorus and drought stress on water use efficiency, relative water content and proline accumulation rate of Coriander (Coriandrum sativum L.). J Med Plants Res 2008; 2: 125-31.

[13] Maiquetia M, Caceres A, Herrera A. Mycorrhization and phosphorus nutrition affect water relations and CAM induction by drought in seedlings of Clusia minor. Annals Botany 2009; 103:525-32.

[14] Becard G, Doner LW, Rolin DB, Douds DD, Pfeffer PE. Identification and quantification of trehalose in vesicular-arbuscular mycorrhizal fungi by in vivo ${ }^{13} \mathrm{C}$ NMR and HPLC analyses. New Phytol 1991; 118: 547-52.

[15] Fajardo Lopez M, Männer P, Willmann A, Hampp R, Nehls U. Increased trehalose biosynthesis in Hartig net hyphae of ectomycorrhizas. New Phytol 2007; 174: 389-98.

[16] Pfeffer PE, Douds DD, Bücking H, Schwartz DP, Shachar-Hill Y. The fungus does not transfer carbon to or between roots in an arbuscular mycorrhizal symbiosis. New Phytol 2004; 163: 617-27.

[17] Pedreschi F, Aguilera JM. Viability of dry Trichoderma harzianum spores under storage. Bioprocess Eng 1997; 17: 177-83.

[18] Fillinger S, Chaveroche MK, van Dijck P, et al. Trehalose is required for the acquisition of tolerance to a variety of stresses in the filamentous fungus Aspergillus nidulans. Microbiology 2001; 147: 1851-62.

[19] Kawai Y, Yamamoto Y. Increase in the formation and nitrogen fixation of soybean nodules by vesicular-arbuscular mycorrhiza. Plant Cell Physiol 1986; 27: 399-405.

[20] Antunes PM, de Varennes A, Zhang T, Goss MJ. The tripartite symbiosis formed by indigenous arbuscular mycorrhizal fungi, Bradyrhizobium japonicum and soya bean under field conditions. J Agro Crop Sci 2006; 192:373-8.

[21] Macias-Rodriguez L, Quero E, Lopez MG. Carbohydrate differences in strawberry crowns and fruit (Fragaria $\times$ ananassa) during plant development. J Agric Food Chem 2002; 50: 3317-21.

[22] Holmström KO, Mäntylä E, Welin B, Mandal A, Palva ET, Tunnela OE, Londesborough J. Drought tolerance in tobacco. Nature 1996; 379: 683-4.

[23] Goddijn O, Verwoerd TC, Voogd E, et al. Inhibition of trehalase activity enhances trehalose accumulation in transgenic plants. Plant Physiol 1997; 113: 181-90.

[24] Wang YJ, Hao YJ, Zhang ZG, Chen T, Zhang JS, Chen SY. Isolation of trehalose-6-phosphate phosphatase gene from tobacco and its functional analysis in yeast cells. J Plant Physiol 2005; 162: 215-23.

[25] Garg AK, Kim JK, Ranwala A, Wu R. Accumulation of trehalose in transgenic indica rice using bifunctional fusion enzyme of trehalose-6-phosphate synthase and trehalose-6-phosphate phosphatase of Escherichia coli. Rice Genet News1 2009; 18: 97-89.

[26] NCBI. Avaaiable from: http://www.ncbi.nlm.nih.gov/sites/entrez/. [Accessed on May 6, 2009].

[27] Goddijn O, Smeekens S. Sensing trehalose biosynthesis in plants. Plant J 1998; 14: 143-6.

[28] Penna S. Building stress tolerance through over-producing trehalose in transgenic plants. Trends Plant Sci 2003; 8: 355-7.

[29] Karim S, Aronsson H, Ericson H, et al. Improved drought tolerance without undesired side effects in transgenic plants producing trehalose. Plant Mol Biol 2007; 64: 371-86.

[30] Almeida AM, Cardoso LA, Santos DM, Torne JM, Fevereiro PS. Trehalose and its applications in plant biotechnology. In Vitro Cell Dev Biol Plant 2007; 43: 167-77.

[31] Iordachescu M, Imai R. Trehalose biosynthesis in response to abiotic stresses. J Integrative Plant Biol 2008; 50: 1223-9. 
[32] Abdel-Fattah GM, Fatma, Migahed FF, Ibrahim AH. Interactive effects of endomycorrhizal fungus Glomus etunicatum and phosphorous fertilization on growth and metabolic activities of broad beans plants under drought stress conditions. Pak J Biol Sci 2002; 5: 835-41.
[33]

Bethlenfalvay GJ, Pacovsky RS, Bayne HG, Stafford AE. Interactions between nitrogen fixation, mycorrhizal colonization, and host-plant growth in the Phaseolus-Rhizobium-Glomus symbiosis. Plant Physiol 1982; 70: 446-50.

Received: May 31, 2010

Revised: June 17, 2010

Accepted: June 25, 2010

(C) Ballesteros-Almanza et al.; Licensee Bentham Open.

This is an open access article licensed under the terms of the Creative Commons Attribution Non-Commercial License (http://creativecommons.org/licenses/ by-nc/3.0/) which permits unrestricted, non-commercial use, distribution and reproduction in any medium, provided the work is properly cited. 